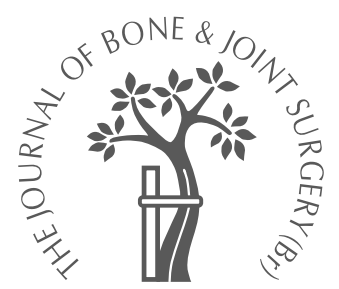

B. Daley,

A. T. Doherty,

B. Fairman,

C. P. Case

From Southmead

Hospital, Bristol, England
B. Daley, BSc

A. T. Doherty, PhD

C. P. Case, MSc, DPhil, MRC Path

Bristol Implant Research

Centre, Avon Orthopaedic

Centre, Southmead Hospital,

Bristol BS10 5NB, UK.

B. Fairman, PhD

Laboratory of Government

Chemist, Queen Road,

Teddington, Middlesex

TW11 OLY, UK.

Correspondence should be addressed to $\mathrm{Dr}$ C. P. Case.

(C)2004 British Editorial

Society of Bone and

Joint Surgery

doi:10.1302/0301-620X.86B4

$14368 \$ 2.00$

$J$ Bone Joint Surg $[\mathrm{Br}]$

2004;86-B:598-606.

Received 27 March 2003

Accepted after revision

15 October 2003

\title{
Wear debris from hip or knee replacements causes chromosomal damage in human cells in tissue culture
}

Wear debris was extracted from 21 worn hip and knee replacements. Its mutagenic effects were tested on human cells in tissue culture using the micronucleus assay and fluorescent in situ hybridisation.

The extracted wear debris increased the level of micronuclei in a linear dose-dependent manner but with a tenfold difference between samples. The concentration of titanium +/vanadium and aluminium within the wear debris was linearly related both to the level of centromere-positive micronuclei in tissue culture, indicating an aneuploid event, and to the level of aneuploidy in vivo in peripheral blood lymphocytes. The concentration of cobalt and chromium +/- nickel and molybdenum in the wear debris correlated with the total index of micronuclei in tissue culture, both centromere-positive and centromere-negative i.e. both chromosomal breakage and aneuploidy events.

The results show that wear debris can damage chromosomes in a dose-dependent manner which is specific to the type of metal. The results from studies in vitro correlate with those in vivo and suggest that the wear debris from a worn implant is at least partly responsible for the chromosomal damage which is seen in vivo.

Joint replacements liberate soluble $^{1}$ and particulate $^{2}$ wear debris from their surfaces especially when they become loose. Soluble metal is liberated into the blood and excreted in the urine. Increases in the concentration of chromium of up to 27-fold in serum and 35fold in urine have been reported. ${ }^{3}$ Particulate wear debris accumulates in periprosthetic tissues and in the local bone marrow. It is systemically disseminated to local and distant lymph nodes, the liver and the spleen. The concentration of cobalt has been reported to increase up to 45 000-fold in the bone marrow. ${ }^{2}$ Particulate wear debris consists of metal, cement and polyethylene and is located both intracellularly, particularly in macrophages, and extracellularly. There is a wide range in the size of wear debris from $100 \mu \mathrm{m}$ to a few $\mathrm{nm}$ in diameter.

In the short term wear debris induces an inflammatory reaction, which damages the local tissues and bone and leads to aseptic loosening. In the long term there has been concern that prolonged exposure to the cobalt, nickel, aluminium, vanadium and titanium which is present in the metal alloy could also be damaging. The risks of immune reactions including hypersensitivity, ${ }^{4}$ toxicity, ${ }^{3}$ carcinogenesis ${ }^{5-9}$ and mutagenicity ${ }^{10,11}$ have been highlighted but not fully clarified.
Ionic chromium, cobalt, nickel, vanadium, aluminium and titanium have mutagenic actions on cells in tissue culture. Chromium (VI) and nickel (II) are classified as proven carcinogens. Metallic nickel and cobalt are possibly carcinogenic while metallic chromium is not classifiable. The genotoxic effects of the metal ions are thought to be mediated by either direct action, causing DNA breaks through attacks on free radicals or by an indirect effect by inhibiting the repair of DNA. ${ }^{10-12}$

In patients at revision arthroplasty there is evidence for mutagenic damage in bone marrow and peripheral blood lymphocytes. A twofold increase in asymmetrical (lethal) chromosomal aberrations is present in femoral bone marrow adjacent to worn metal-on-plastic prostheses when compared with bone marrow not directly exposed to wear debris and derived either from the iliac crest from the same patient or the femur from a patient at primary arthroplasty. ${ }^{13}$

A similar increase in symmetrical (nonlethal) aberrations is present in peripheral blood lymphocytes with a threefold increase in aneuploidy and a twofold increase in chromosomal translocations. The type of damage observed depends on the composition of the prosthesis. In patients with titanium-vana- 
Table I. Details of the 21 patients

\begin{tabular}{|c|c|c|c|c|c|c|}
\hline Case & Age & Gender & Alloy & $\begin{array}{l}\text { Type of } \\
\text { prosthesis }\end{array}$ & $\begin{array}{l}\text { Time to } \\
\text { revision (yrs) }\end{array}$ & Clinical details \\
\hline 1 & 85 & $\mathrm{~F}$ & $\mathrm{Co}-\mathrm{Cr}$ & Kinematic & 12 & \\
\hline 2 & 81 & $\mathrm{~F}$ & $\mathrm{Ti}$ & D-Series & 14 & \\
\hline 3 & 73 & $\mathrm{~F}$ & $\mathrm{Ti}$ & Müller/Galante & & \\
\hline 4 & & $\mathrm{M}$ & $\mathrm{Ti}$ & Biomet & & \\
\hline 5 & 41 & $\mathrm{M}$ & Mixed & Stanmore/HG & 3 & Cup rubbing on head \\
\hline 6 & 82 & $\mathrm{~F}$ & $\mathrm{Co}-\mathrm{Cr}$ & & & \\
\hline 7 & 84 & $\mathrm{M}$ & $\mathrm{Ti}$ & D-Series & 16 & Severe acetabular lysis \\
\hline 8 & 71 & $\mathrm{~F}$ & $\mathrm{Ti}$ & Ring & 10.5 & Acetabular lysis \\
\hline 9 & 70 & $\mathrm{M}$ & Steel & Charnley & 10.5 & Loose stem \\
\hline 10 & 87 & $\mathrm{~F}$ & Steel & Charnley & 17 & Periprosthetic fracture \\
\hline 11 & 80 & $\mathrm{~F}$ & $\mathrm{Ti}$ & D-Series & & \\
\hline 12 & 65 & $\mathrm{M}$ & $\mathrm{Co}-\mathrm{Cr}$ & Oxford & 2 & Loose tibial component \\
\hline 13 & 77 & $\mathrm{M}$ & $\mathrm{Co}-\mathrm{Cr}$ & Müller & & Loose stem \\
\hline 14 & 74 & $\mathrm{M}$ & $\mathrm{Ti}$ & D-Series & 14.5 & $\begin{array}{l}\text { Emergency admission } \\
\text { loosening }\end{array}$ \\
\hline 15 & 81 & $\mathrm{~F}$ & $\mathrm{Ti}$ & D-Series & 10 & Loose stem osteolysis \\
\hline 16 & 86 & $\mathrm{~F}$ & $\mathrm{Co}-\mathrm{Cr}$ & Howse & & \\
\hline 17 & 89 & $\mathrm{~F}$ & $\mathrm{Ti}$ & J \& J Exeter & & \\
\hline 18 & 71 & $M$ & $\mathrm{Ti}$ & D-Series & 10 & \\
\hline 19 & 81 & $\mathrm{M}$ & $\mathrm{Co}-\mathrm{Cr}$ & Kinematic & 11 & $\begin{array}{l}\text { Severe wear polyethyl- } \\
\text { ene }\end{array}$ \\
\hline 20 & 77 & $\mathrm{~F}$ & $\mathrm{Ti}$ & Ring & 11 & Osteolysis \\
\hline 21 & 76 & $M$ & $\mathrm{Co}-\mathrm{Cr}$ & Kinemax & 9 & Periprosthetic fracture \\
\hline
\end{tabular}

dium-aluminium prostheses there is a fivefold increase in aneuploidy with no increase in chromosomal translocations. In those with worn cobalt-chrome prostheses there is a 3.5 -fold increase in chromosomal translocations and a smaller 2.5 -fold increase in aneuploidy. ${ }^{14}$

While these data suggest that wear debris may cause genetic damage, there are a number of paradoxes apparent in these studies. Only a third of the patients at revision arthroplasty showed an increase above control of asymmetrical aberrations in the bone marrow ${ }^{13}$ and only half showed an increase in symmetrical aberrations in the peripheral blood. ${ }^{14}$ It is therefore pertinent to ask how much of this genetic damage is due to other factors within the patient and how much is due to the wear debris? Is all wear debris able to cause mutagenetic damage?

In an attempt to answer this we have followed the principles of genotoxicity testing in which a variety of assays is available to determine the genotoxic or mutagenic potential of a xenobiotic compound. We have used the in vitro micronucleus assay with centromeric labelling since this is a standard test for mutagenicity ${ }^{15,16}$ with particular relevance for particulates. ${ }^{17}$ It detects both whole chromosomal (aneugenic) and DNA/chromosomal breakage (clastogenic) damage at sublethal doses and we have applied it to human cells in tissue culture after being exposed to wear debris for 24 hours (one cell cycle). We have compared the level of mutagenic damage in tissue culture with that detected in the peripheral blood of the same patients from whom the wear debris had been extracted ${ }^{14}$ and with the metallic and elemental composition of the wear debris as detected by high-resolution inductively-coupled plasma mass spectrometry.

\section{Patients and Methods}

We studied 21 consecutive patients with osteoarthritis undergoing revision arthroplasty for aseptic loosening. Details of the patients are shown in Table I and consent was obtained from all.

Chromosomal painting. Each patient was evaluated for stable chromosomal aberrations (translocations) by simultaneous painting of chromosomes 1,2 and 3. Fluorescent in situ hybridisation analysis was performed with commercial human chromosomal paints (Cambio, Cambridge, UK) according to the techniques previously described by Ellard et al. ${ }^{18}$

We examined 300 metaphase spreads per patient on duplicate slides. Fluorescence microscopy was performed using an Olympus BX60 microscope equipped with a single band-pass filter (Olympus, Middlesex, UK) to visualise the green and red fluorochromes and a triple bandpass filter (Chromatechnology, Brattleboro, Vermont) which allows the simultaneous detection of DAPI (D4'-6diamicline-2' phenylindote dihydrochloride, stains DNA blue under UV light), FITC (fluorescein isothiocynate, a fluorescent congugate, green in colour) and Texas Red (a fluorescent congugate, red in colour). A Cytovision digitalimaging system (Applied Imaging Ltd, Santa Clara, California) was used to capture, digitise, annotate and print multicolour images.

Extraction of wear debris. Approximately $3 \mathrm{~cm}^{3}$ of periprosthetic tissue with grey/black visible metallosis were removed from each of the 21 patients. Previous experiments have shown that tissue may contain metal, plastic and cement wear debris from a loose or worn metal-onpolyethylene joint replacement. ${ }^{19}$ 
Table II. Concentration (parts per million, $\mu \mathrm{g} / \mathrm{g}$ ) of aluminium, titanium, vanadium, chromium, cobalt, nickel, molybdenum, zirconium and barium in wear debris (detection limits DL are shown at the top of the table). Also shown is the total concentration of all metals apart from barium and zirconium, to give the total concentration of prosthetic metal and the sum of $\mathrm{Ti}, \mathrm{A} 1$ and $\mathrm{V}$ and the sum of $\mathrm{Cr}$, Co, $\mathrm{Ni}$ and $\mathrm{Mo}$

\begin{tabular}{|c|c|c|c|c|c|c|c|c|c|c|c|}
\hline $\begin{array}{l}\text { DL } \\
\text { Exp No }\end{array}$ & $\begin{array}{l}0.02 \\
\text { Al }\end{array}$ & $\begin{array}{l}0.04 \\
\mathrm{Ti}\end{array}$ & $\begin{array}{l}0.02 \\
V\end{array}$ & $\begin{array}{l}0.02 \\
\mathrm{Cr}\end{array}$ & $\begin{array}{l}0.02 \\
\text { Co }\end{array}$ & $\begin{array}{l}0.06 \\
\mathrm{Ni}\end{array}$ & $\begin{array}{l}0.01 \\
\text { Mo }\end{array}$ & $\begin{array}{l}0.07 \\
\mathrm{Zr}\end{array}$ & $\begin{array}{l}0.03 \\
\mathrm{Ba}\end{array}$ & $\mathrm{Ti}+\mathrm{Al}+\mathrm{V}$ & $\mathrm{Cr}+\mathrm{Co}+\mathrm{Ni}+\mathrm{Mo}$ \\
\hline 2 & 205 & 1819 & 101 & 6.74 & 0.02 & 0.47 & 0.01 & 474 & 1.05 & 2125 & 7 \\
\hline 5 & 72.7 & 6587 & 2.63 & 41.00 & 61.0 & 1.81 & 5.96 & 0.07 & 65.8 & 6662 & 110 \\
\hline 6 & 29.5 & 0.93 & 0.26 & 188 & 166 & 3.34 & 21.5 & 17.9 & 0.51 & 31 & 378 \\
\hline 7 & 4.56 & 37.9 & 1.71 & 0.51 & 0.02 & 0.06 & 0.01 & 0.07 & 2.07 & 44 & 0.6 \\
\hline 8 & 17.0 & 148 & 6.92 & 7.45 & 0.26 & 0.67 & 0.84 & 0.61 & 2.29 & 172 & 9 \\
\hline 10 & 7.36 & 2.21 & 0.22 & 24.9 & 0.02 & 7.32 & 1.66 & 485 & 0.33 & 10 & 34 \\
\hline 11 & 178 & 1756 & 81.9 & 5.02 & 0.05 & 0.39 & 0.01 & 143 & 0.52 & 2016 & 5.5 \\
\hline 13 & 24.3 & 102 & 3.56 & 60.6 & 98.3 & 0.13 & 10.1 & 145 & 0.28 & 130 & 169 \\
\hline 14 & 204 & 2345 & 98.2 & 36.6 & 6.81 & 4.53 & 2.04 & 83.4 & 0.72 & 2647 & 50 \\
\hline 15 & 250 & 2880 & 155 & 8.00 & 0.02 & 0.52 & 0.07 & 55.5 & 0.86 & 3285 & 9 \\
\hline 16 & 11.8 & 0.07 & 0.02 & 11.5 & 0.04 & 4.45 & 0.57 & 4.43 & 13.85 & 12 & 17 \\
\hline 17 & 249 & 3065 & 137 & 4.30 & 0.17 & 0.32 & 0.01 & 106 & 1.08 & 3451 & 5 \\
\hline 18 & 50.1 & 605 & 29.5 & 2.10 & 0.07 & 0.55 & 0.02 & 256 & 0.19 & 685 & 2.7 \\
\hline 19 & 16.5 & 1.67 & 0.66 & 0.02 & 0.02 & 9.21 & 210 & 68.9 & 1.26 & 19 & 219 \\
\hline 20 & 79.4 & 912 & 34.9 & 6.79 & 0.09 & 0.23 & 0.10 & 6.19 & 0.67 & 1026 & 7 \\
\hline 21 & 7.64 & 1.21 & 0.10 & 23.0 & 28.3 & 0.51 & 3.16 & 153 & 0.42 & 9 & 55 \\
\hline
\end{tabular}

The tissue was stored at $-80^{\circ} \mathrm{C}$ until needed. It was then homogenised and placed in a sample pot with warmed $1 \%$ trypsin and collagenase $(250 \mu \mathrm{g} / \mathrm{ml})$, gently mixed and allowed to digest for 24 hours in an incubator at $37^{\circ} \mathrm{C}$. The digested wear debris was layered onto histopaque (SigmaAldrich, Dorset, UK) and centrifuged for 25 minutes at $3500 \mathrm{rpm}$. Two separate fractions of wear debris were visible and removed samples were then washed in phosphatebuffered saline (PBS) and the centrifuged pellet stored at $-20^{\circ} \mathrm{C}$. Both the top and bottom fractions of the wear debris were pooled before cell treatment since dose-finding experiments had revealed little difference between the fractions. Polarised light microscopy indicated that particles of polyethylene were present in the top fraction.

Cell culture. Human pooled primary amnion cells were grown in Hams F10 media supplemented with $10 \%$ fetal bovine serum, $2 \%$ L-glutamine, $1 \%$ Ultroser and $0.03 \%$ of penicillin/streptomycin. The cells were routinely subcultured with versene/trypsin solution in $75 \mathrm{~cm}^{2}$ flasks. They were grown for one month and then discarded.

Twelve $25 \mathrm{~cm}^{2}$ flasks were set up for each treatment. Before treatment $1 \times 10^{5}$ cells were allowed to settle for 24 hours and treated for 24 hours simultaneously with a suspension of wear debris and cytochalasin $\mathrm{B}(6 \mu \mathrm{g} / \mathrm{ml})$ at $37^{\circ} \mathrm{C}$ before harvesting. Wear debris was suspended in $1 \mathrm{ml}$ of PBS and added to duplicate flasks of amnion cells using four doses (50 to $300 \mu \mathrm{l}$ ) of wear debris suspended in PBS. Two control flasks contained no wear debris, one flask had $300 \mu \mathrm{l}$ of PBS as a negative control, and one had $10 \mu \mathrm{l}$ of mitomycin-C as a positive control. All the flasks were incubated with $15 \mu$ l of cytochalasin B to give a final concentration of $6 \mu \mathrm{g} / \mathrm{ml}$.

At harvest the cells were washed twice in $2 \mathrm{ml}$ of Hanks's balanced salt solution (Sigma Aldrich) and then $1.5 \mathrm{mls}$ of versene/trypsin was added to detach the cells which were resuspended in $1 \mathrm{ml}$ of media. The cells were then cytospun on to cleaned slides (Shandon Cytospin 4, Shandon-
Thermo, Pittsburgh, Pennsylvania). The slides were fixed in $90 \%$ methanol, stained in 20\% Giemsa (BDH, Leicestershire, UK). Duplicate slides were stored for centromeric labelling. The slides in each case were scored randomly at 1000x magnification under oil immersion. For each replicate 1000 binucleate cells were scored and the numbers of mononucleate, tritetra and multi-nucleates were noted. Micronuclei were determined to be less than one-third of the size of the main nuclei.

Replicate cultures $(5 \mathrm{ml})$ of cells from peripheral blood were initiated by the addition of $5 \mathrm{ml}$ of McCoys $5 \mathrm{~A}$ (Gibco, Invitrogen, Paisley, Pennsylvania) supplemented with $25 \mathrm{mM}$ Hepes, $12.5 \%$ fetal bovine serum, penicillin $(100 \mathrm{U} / \mathrm{ml})$, and streptomycin $(100 \mathrm{U} / \mathrm{ml})$ with phytohaemagglutinin $(1.25 \%$, Glaxo-Wellcome, Murex Biotech, Kent, UK). Duplicate cultures for each patient were incubated at $37^{\circ} \mathrm{C}$. Seventy hours after initiation $2.2 \mu \mathrm{g} / \mathrm{ml}$ of colchicine (Gibco) were added and the cultures were incubated for a further 45 minutes. The cells were harvested and slides prepared in a standard assay as described in Ellard et al. ${ }^{18}$

Centromeric labelling was carried out according to the procedure of Doherty et al. ${ }^{20}$ The cells were counterstained with DAPI in Vectashield mountant and scored on a Olympus BX60 microscope with use of a single Texas Red and triple band-pass filters.

Metal analysis. Samples of wear debris material were weighed, then dried down and weighed again to obtain the solid content of each sample. The dried plugs of particulate wear debris (3 to $100 \mathrm{mg}$ ) were then dissolved in $4 \mathrm{ml}$ of nitric acid and $1 \mathrm{ml}$ of hydrochloric acid (J.T. Baker, Phillipsburg, New Jersey) using a microwave digestion procedure (Perkin Elmer, Beaconsfield, UK).

There was sufficient residual wear debris in 16 of the 21 samples to obtain accurate measurements of the metal content. The concentration of chromium, cobalt, nickel, titanium, aluminium, molybdenum, calcium, phosphorus, 

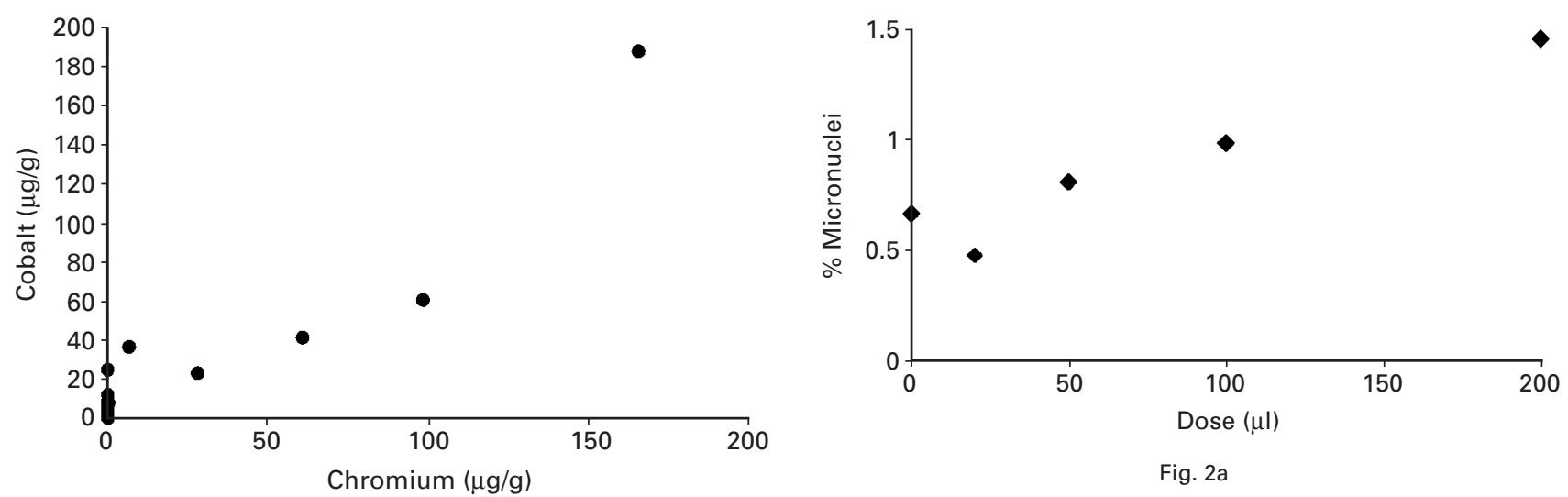

Fig. 1a
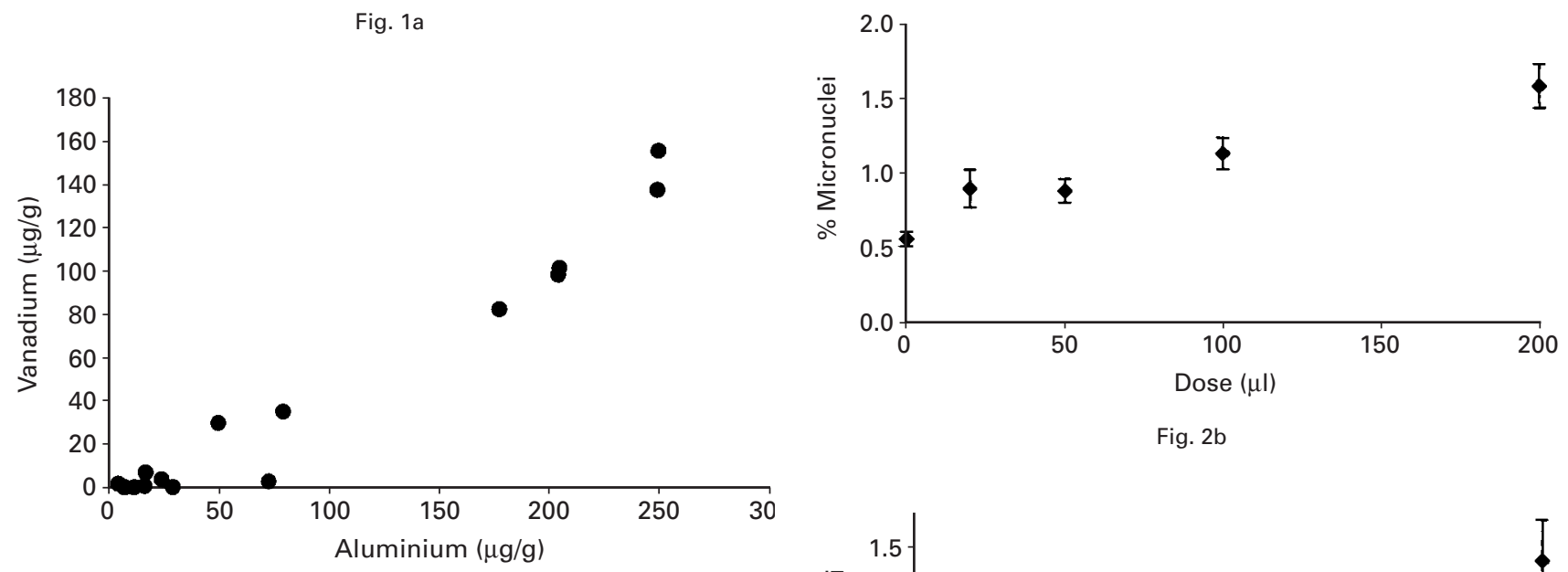

Fig. 1b

Relationship of the concentrations (parts per million) of metals in the extracted wear debris showing a) cobalt plotted against chromium and b) vanadium plotted against aluminium.

barium, zirconium and vanadium were determined using a double focusing, magnetic sector inductively-coupled plasma mass spectrometer (HR-ICP-MS) (Element; Finnigan MAT, Bremen, Germany) using the method described by Case et al. ${ }^{21}$ The instrument was operated following a UKAS accredited method (LGC internal reference number INS/A1-0008).

A multi-element $10 \mu \mathrm{g} \cdot \mathrm{ml}^{-1}$ stock standard solution was prepared in $5 \%$ ultra pure $\mathrm{HNO}_{3}$ (Ultrex grade; J.T. Baker) from commercial single element $1000 \pm 3 * \mu \mathrm{g} \cdot \mathrm{ml}^{-1}$ standard solutions (Spec CertiPrep Inc, Metuchen, New Jersey) from which daily standards were prepared by serial dilution in $1 \% \mathrm{HNO}_{3} .{ }^{1}$ An internal standard, $\mathrm{Rh}$ (Spec CertiPrep Inc) was added on-line to all standard and sample solutions through a T-piece at a concentration of $10 \mathrm{ng} \cdot \mathrm{ml}^{-1}$ to correct for instrument drift and matrix effects in a continuous flow system. Calibration was achieved by external calibration using standard solutions of $0.1,0.2,0.5,0.75$ and $1 \mathrm{ng}$ with the calibration curves being calculated using the linear through zero option.

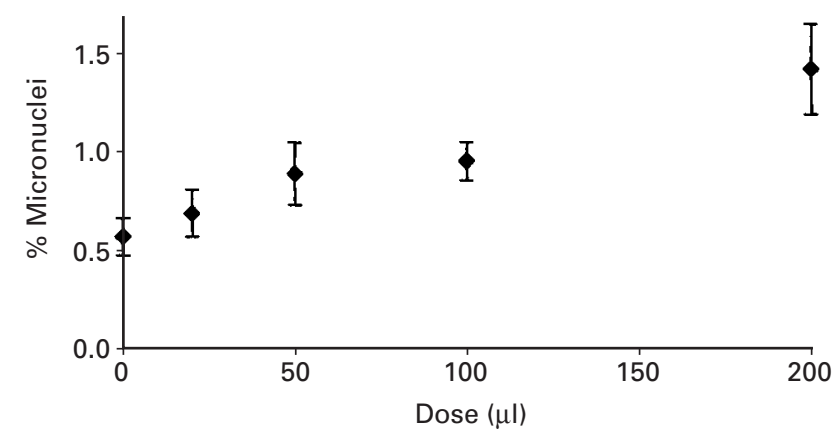

Fig. 2c

Mean ( \pm SD) percentage of micronuclei induced by samples of wear debris from a) stainless steel, b) titanium, vanadium and aluminium and c) cobalt-chrome alloy metal on polyethylene prostheses plotted against the dose of wear debris which was added to the human amnion cells in tissue culture.

\section{Results}

Composition of wear debris. The composition of the samples of wear debris which were extracted from the periprosthetic tissue is shown in Table II. The total metal content was highly variable with a range between 44 and 6772 parts per million. There was a marked contrast in the ratios of the component metals in the wear debris extracted from titanium-aluminium-vanadium prostheses and cobaltchrome prostheses compared with that found in the original prostheses (Fig. 1). The concentration of cobalt correlated linearly with that of chromium $(\mathrm{R}=0.94 ; \mathrm{p}=0.001$, 


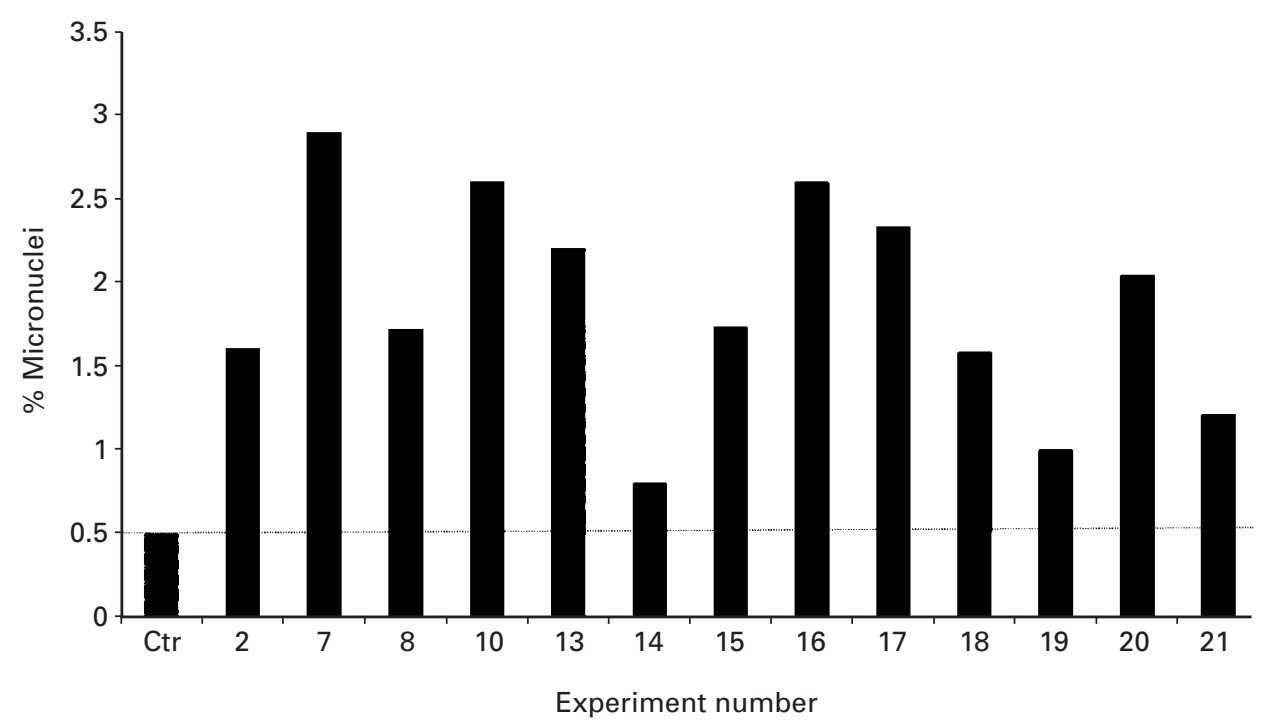

Fig. 3

Induction of micronuclei (expressed as a percentage of micronuclei per binucleate cells) when the same weight of different samples of wear debris was added to human amnion cells in tissue culture. The $\mathrm{x}$-axis shows the sample number of the patient (see Table I). The control value (no wear debris added) is shown at the extreme left and a dotted line has been drawn so that the increase above control can be more readily seen for each sample of wear debris.

Fig 1a). However, the mean ratio of cobalt to chromium in the wear debris, approximately 0.9:1 was quite different from that found in a cobalt-chrome prosthesis, $28 \% \mathrm{Cr}$, $6 \% \mathrm{Mo}, 1 \%$ to $2.5 \% \mathrm{Ni}, 60 \%$ to $62.5 \%$ Co but were similar to that found in whole blood. ${ }^{17}$

There was also a good correlation between the concentrations of titanium, vanadium and aluminium with a high linear correlation. Vanadium correlated linearly with aluminium $(\mathrm{R}=0.94 ; \mathrm{p}=0.001 ;$ Fig $1 \mathrm{~b})$ and titanium with vanadium $(\mathrm{R}=0.57 ; \mathrm{p}=0.02)$ and aluminium $(\mathrm{R}=0.94 ; \mathrm{p}$ $=0.001)$. In contrast to cobalt chrome, the mean ratio of titanium to vanadium to aluminium $(88: 7: 4)$ was very similar to that found in the prosthesis $(89.47 \% \mathrm{Ti}, 6 \% \mathrm{~A} 1$, $4 \% \mathrm{~V})$.

Induction of micronuclei. With increasing dose of wear debris, in 20 of the 21 samples there was a statistically significant linear increase in micronuclei above control values particularly at doses of 100 and $200 \mu \mathrm{l}$. One sample (case 1; Table I) did not have such an increase in micronuclei. In this sample there was an increase at $100 \mu \mathrm{l}$ and at a fixed dose (see Fig. 3) but there was no increase at a higher dose of 200 $\mu$ l. The induction, if all 21 samples were tested, was found to be statistically significant using repeated measures ANOVA $(p=0.003)$. There was no statistical difference in the levels of micronuclei which were induced by the seven cobalt-chrome samples compared with the 11 titanium alloy samples (repeated measures test $\mathrm{p}=0.2$ ) (Fig. 2). The shape and size of the dose-response curves for the cobaltchrome, titanium-vanadium-aluminium and the two stainless-steel samples were remarkably similar if the data were pooled for each alloy (Fig. 2) and were linear. In four of 11 titanium samples there was a biphasic response with higher levels of micronuclei at $25 \mu \mathrm{l}$ compared with $50 \mu \mathrm{l}$ (Fig. 2) which was noted in only one of seven cobalt-chrome samples.

Despite the similarity of the dose-response curves for the pooled data there was considerable variation between the individual samples in their capacity to induce micronuclei. This was not explained by the differences in the weight of the wear debris suspended in PBS in the previous samples. In order to explore this more carefully we performed a separate experiment using $0.001 \mathrm{~g}$ of each of 13 samples of wear debris, in which there was enough material remaining. At this standard dose the induction of micronuclei above control for each sample varied approximately tenfold from $60 \%$ to just under $600 \%$ (Fig. 3). There was no apparent difference in the induction of micronuclei caused by the cobalt-chrome samples compared with the titanium alloy samples.

Comparison of chromosomal aberrations in vivo and in vitro with composition of wear debris. The previous results have shown that there is a linear relationship between the dose of wear debris and the induction of micronuclei. The slope of this line was calculated for all the individual samples of wear debris and was taken as a measure of their relative activity in inducing micronuclei (Fig. 2). The slopes were compared separately with the concentrations of aluminium, phosphorous, calcium, titanium, vanadium, chromium, cobalt, nickel, zirconium, molybdenum and barium in the wear debris. There was a statistically significant 


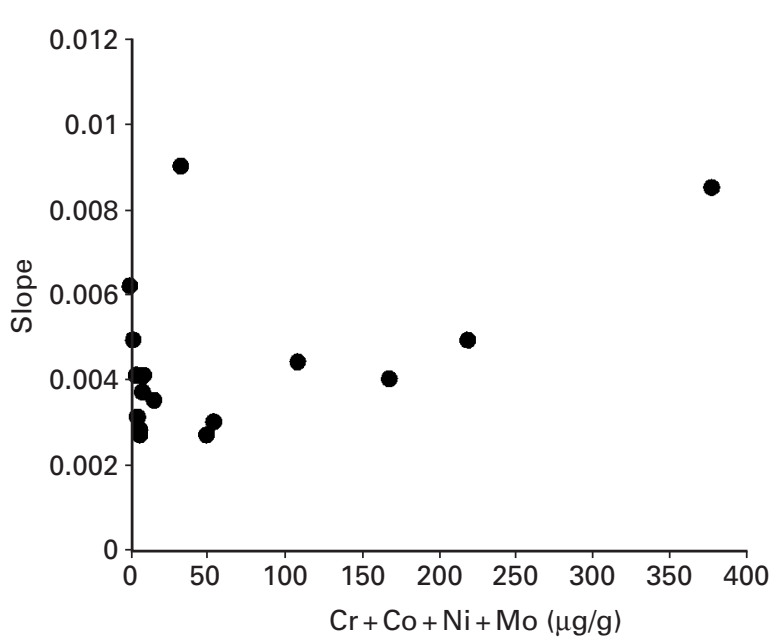

Fig. 4

A dose-response curve for each sample of wear debris obtained by plotting a graph of micronuclei against the dose of wear debris. The slope of this graph was calculated and was taken as a measure of the effectiveness of a given dose of wear debris to induce micronuclei. This slope has been plotted against the sum of concentrations of cobalt, chromium, nickel and molybdenum for each sample of wear debris, expressed as parts per million.

linear relationship between the slopes and the concentrations of cobalt $(\mathrm{R}=0.617, \mathrm{p}=0.011)$, chromium $(\mathrm{R}=$ 0.594, $\mathrm{p}=0.015)$ and zirconium $(\mathrm{R}=0.527, \mathrm{p}=0.037)$ and with cobalt+chromium $(\mathrm{R}=0.615, \mathrm{p}=0.011)$, cobalt+chromium+nickel+molybdenum $(\mathrm{R}=0.641, \mathrm{p}=$ 0.007 ) barium+zirconium $(\mathrm{R}=0.529, \mathrm{p}=0.035)$ but not with the other metals individually or in combination (Fig. 4).

The micronuclei, which were induced in tissue culture, were labelled with centromeric probes to provide additional information about the type of mutagenic damage in vitro.

Centromere-positive micronuclei contain an extra chromosome and therefore reflect an aneuploid event. Centromere-negative micronuclei contain incomplete chromosomal material and therefore reflect a breakage event. The labelling was performed at a standard dose of wear debris of $100 \mu$ l.

The index of centromere-positive micronuclei was significantly correlated with the concentration of titanium $(\mathrm{R}=0.639, \mathrm{p}=0.008)$ and titanium+vanadium+aluminium $(\mathrm{R}=0.614, \mathrm{p}=0.011$ ) (Fig. 5) but not with the other metals individually or in combination. The index of centromerenegative micronuclei was not significantly related to any of the metal concentrations.

The index of aneuploidy in the lymphocytes in peripheral blood from the same patient was correlated with the concentration of titanium $(\mathrm{R}=0.691, \mathrm{p}=0.004)$, and titanium+vanadium+aluminium $(\mathrm{R}=0.68, \mathrm{p}=0.005)$ (Fig. 6) but not the other metals in the patients' wear debris. The

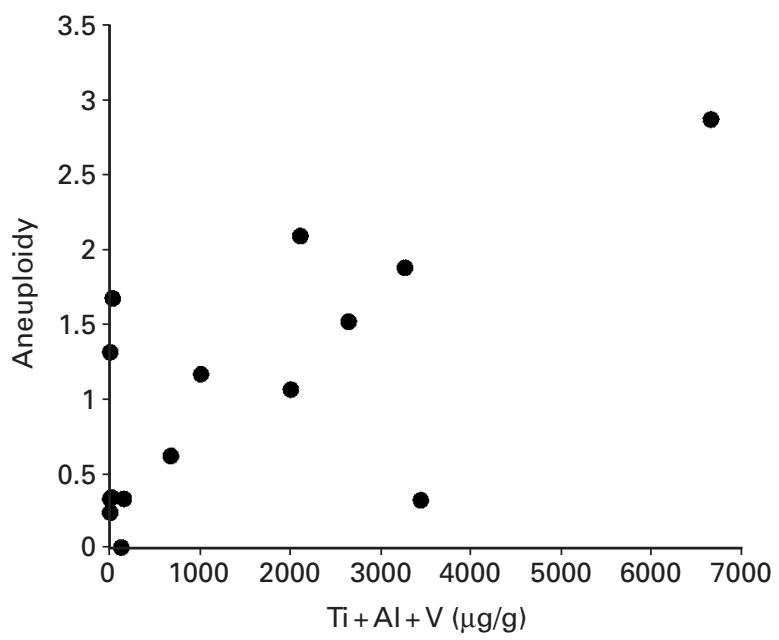

Fig. 5

The index of aneuploidy in each patient's peripheral blood plotted against the sum of the concentrations of titanium, aluminium and vanadium in the same patient's wear debris, expressed as parts per million.

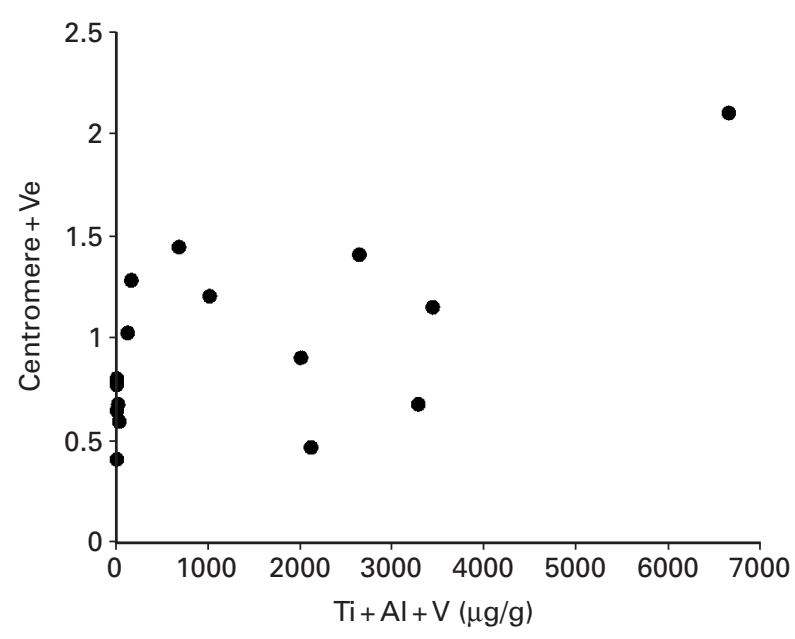

Fig. 6

The index of centromere-positive micronuclei plotted against the sum of the concentrations of titanium, aluminium and vanadium for each sample of wear debris, expressed as parts per million.

index of chromosomal translocations in the peripheral blood lymphocytes was not related to the concentration of any of the metals individually or in combination. The index of aneuploidy added to the index of translocations in the peripheral blood was significantly related to the index of micronuclei in tissue culture using a standard dose of wear debris of $100 \mu \mathrm{l}(\mathrm{R}=0.631, \mathrm{p}=0.015)$. 


\section{Discussion}

In a previous study ${ }^{22}$ we have shown that there is an increase in chromosomal aberrations in patients at revision arthroplasty of metal-on-metal polyethylene prostheses. We also noted that only a proportion of patients at revision arthroplasty showed an increase in chromosomal aberrations in vivo. A third showed an increase in asymmetrical aberrations in bone marrow, ${ }^{13}$ consisting of gaps or breaks to a chromosome or chromatid. Approximately half of the patients showed an increase in symmetrical aberrations in peripheral blood lymphocytes, ${ }^{14}$ consisting of chromosomal translocations and aneuploidy.

It was therefore of interest in this study to determine whether there was any evidence that the wear debris at revision arthroplasty caused the chromosomal damage in human cells. If this was true, it would also be of interest to test if there was any variation in the reactivity of wear debris which may explain why not all patients show an increase in chromosomal aberrations. In other words do patients respond differently because the wear debris is different or because they are different in some way?

The results of our study suggest that particles of wear debris can cause chromosomal aberrations in tissue culture. Furthermore, there are differences in the reactivity of the wear debris in tissue culture and these depend on at least three factors, the dose of the wear debris, the type of alloy in the prosthesis and the relative proportions or concentrations of metal in the wear debris. There is evidence to suggest that some of these factors are also related to the level of damage in vivo. ${ }^{14}$

It is important to emphasise that a tissue-culture system is not an exact model of what happens in vivo. First, there are the obvious limitations of studying any cells in tissue culture, which may be in a different state of differentiation compared with cells in vivo. Secondly, we have extracted particulate wear debris from periprosthetic tissue using the enzymes trypsin and collagenase. We have therefore not tested the same mix of soluble and particulate wear debris which may occur in vivo and we may have destroyed metalloprotein complexes. Thirdly, we have used a 24-hour exposure and have therefore detected only short-term effects (see below). Fourthly, we chose to study pooled human amnion cells rather than bone-marrow cells. We did this for a number of reasons. Amnion cells are naïve with regard to previous exposure to genotoxic agents. They are not subject to complex patterns of differentiation in culture like bone-marrow cells. They are not transformed cells and therefore are not carrying underlying mutations. It was convenient to use pooled cells which would avoid unusual results because of the specific individual genotype. Finally, our exposure of amnion cells could not be expected to imitate any complex cellular interactions which may take place in vivo, e.g. between macrophages containing wear debris and adjacent lymphoid cells and their precursors. In our experiments there was a statistically significant and linear dose relationship between the number of micronuclei and the amount of wear debris. We did not detect thresholds for mutagenic effects at the doses tested. The highest levels of wear debris are found near the prosthesis and most of the short-term chromosomal damage may well occur at this location. ${ }^{2}$ Wear debris is systemically disseminated at a lower concentration to local and distant lymph nodes, liver and spleen.

Chromosomal damage may occur in all of these sites but the greatest number of damaged lymphocytes in the circulation is likely to be derived from the local bone marrow adjacent to the prosthesis. In keeping with this is the greater number of asymmetrical aberrations in bone marrow from the femur compared with the iliac crest at revision of worn hip replacements. ${ }^{13}$

Long-term chromosomal damage may occur simultaneously by low doses of wear debris because of the interesting mechanism of chromosomal instability. ${ }^{23,24}$ This was first described in cells which had been exposed to low doses of radiation. These maintain a normal genotype after exposure but then develop new chromosomal aberrations after 10 to 30 cell divisions. This effect has been proposed as a mechanism for the long-term leukaemic effects of radiation. The same mechanism has been noted in human cells exposed to wear debris. ${ }^{25}$ Recently, Lorrimore et al $^{26}$ have suggested that macrophages may be activated after exposure to radiation and cause chromosomal instability in neighbouring bone-marrow cells via a bystander effect. Such a mechanism may also be pertinent for macrophages which have ingested wear debris when disseminated to bone marrow, lymph nodes, liver and spleen.

A previous study ${ }^{22}$ reported that only a third of patients at revision arthroplasty showed an increase in chromosomal aberrations in the bone marrow and approximately a half showed an increase in chromosomal aberrations in the peripheral blood. This study suggests that this is not likely to be explained by these patients containing wear debris with no reactivity but rather with less reactivity. Only one sample of 21 had no statistically significant linear increase in micronuclei in tissue culture with increasing dose of wear debris. There was, however, a very large variation in the reactivity of the samples of wear debris if tested at a standard dose with the increase of micronuclei ranging from $60 \%$ to $600 \%$. It is clear, at least in tissue culture, that the effect of the wear debris depends on the dose and the reactivity of the sample of wear debris.

At least part of this 'reactivity' was due to the type of metal and its 'concentration' in the particulate wear debris. It is appreciated that the term concentration is inexact in this respect since we measured the overall relative content of metal per weight of wear debris in a particulate sample. Samples of equivalent metal content may have very different numbers, sizes, shapes and surface areas of metal particles all of which may influence the biological outcome. However, even surface areas of metal exposed to amnion cells in culture would be extremely difficult to calculate and the overall content per weight is a useful approximation. 
In previous studies it was noted that the type of metal influenced the type of chromosomal aberrations. Patients with worn titanium-vanadium-aluminium prostheses had a fivefold increase in aneuploidy in peripheral blood lymphocytes with no change in chromosomal translocations. By contrast, those with worn cobalt-chrome prostheses had an increase of 3.5-fold in chromosomal translocations and a 2.5 -fold increase in aneuploidy. This differential effect in vivo has been confirmed in this study in vitro. ${ }^{19}$

Titanium alloy caused an increase in centromere-positive micronuclei with no change in centromere-negative micronuclei. ${ }^{19}$ Since the presence of a centromere in the micronucleus suggests the presence of a whole chromosome rather than a chromosomal fragment this therefore implies the presence of aneuploidy in that cell.

Moreover, the level of centromere-positive micronuclei was only positively correlated with the concentration of titanium or the combination of titanium, vanadium and aluminium in the wear debris which was added to the human amnion cells in tissue culture. This implies not only a dose-dependant effect of wear debris in causing mutagenic damage but also a very specific effect of titanium in causing aneuploidy. The fact that the level of aneuploidy in the patients' peripheral blood lymphocytes at revision arthroplasty also correlated with exactly these metal types is highly suggestive that the titanium alloy is causing aneuploidy in the patients in a dose-dependent manner.

Cobalt-chrome alloy, by contrast, caused an increase in both centromere-positive and centromere-negative micronuclei, i.e. equivalent to both aneuploid and chromosomal breakage events. ${ }^{26}$ This is very much in keeping with the increase in both aneuploidy and chromosomal translocations in patients at revision surgery of a cobalt-chrome prosthesis. ${ }^{14}$ It was of interest in our study that only the concentrations of cobalt or chromium or the combination of cobalt, chromium, nickel and molybdenum in the wear debris were correlated with the slope of the total micronucleus induction with increasing dose of wear debris. The induction of micronuclei with increasing dose of wear debris was both visually and statistically a linear relationship.

Therefore the slope of the induction with increasing dose may be taken as a convenient way of averaging the overall activity of a sample of wear debris. A sample with a higher slope would therefore be more effective at inducing micronuclei than a sample with a lesser slope. In this context therefore there is a very specific effect of cobalt-chrome alloy in increasing the activity of all types of micronucleus, both centromere-positive and centromere-negative. This is entirely in keeping with the changes seen in vivo, which involve an increase in both chromosomal translocations and aneuploidy. It is highly suggestive that this effect, like that of titanium alloy, is specifically caused by the metal in the wear debris in a dose- and concentration-dependant manner.
The correlation between the level of micronuclei in tissue culture and the sum of aneuploidy and chromosomal translocations in peripheral blood cells is further evidence that these relationships which we have seen in tissue culture provide reliable information as to what is happening in the patient. It suggests that the amount of chromosomal damage in any patient at revision arthroplasty depends on the amount of wear debris, the type of metal alloy which it contains and the concentration of, particularly, titanium, cobalt and chromium within the wear debris.

The authors would like to thank Dr Tony Hughes for his help with the statistical analysis. The work was partly supported by a grant from the Showering Foundation.

No benefits in any form have been received or will be received from a com mercial party related directly or indirectly to the subject of this article.

\section{References}

1. Sunderman SW Jr, Hopfur SM, Swift T, et al. Cobalt, chromium and nickel concentrations, body fluids of patients with porous-coated knee or hip prostheses. J Orthop Res 1989;7:307-15.

2. Case CP, Langkamer VG, James C, et al. Widespread dissemination of metal debris from implants. J Bone Joint Surg [Br] 1994;76-B:701-12.

3. Jacobs JJ, Hallab NJ, Skipor AK, et al. Metallic wear and corrosion products: biological implications in Metasul metal on metal bearing. In: Reiker C. Windler M, Wyss U, eds. Metasul: a metal-on-metal bearing, Gottingen: Hans Huber, 1999.

4. Hallab N, Merritt K, Jacobs JJ. Metal sensitivity in patients with orthopaedic implants. J Bone Joint Surg [Am] 2001;83-A:428-36.

5. Gillespie WJ, Frampton CMA, Henderson RJ, Ryan PM. The incidence of cancer following total hip replacement. J Bone Joint Surg [Br] 1988;70-B:539-42.

6. Visuri T, Koskenvuo M. Cancer risk after Mckee-Farrar total hip replacment. Orthopaedics 1991;14:137-42.

7. Visuri T, Pukkala E, Paavolainen P, Pulkkinen P, Riska EB. Cancer risk after metal on metal and polyethylene on metal total hip arthroplasty. Clin Orthop 1996:329 (Suppl):280-9

8. Gillespie WJ, Henry DA, O'Connell DL, et al. Development of hematopoietic cancers after implantation of total joint replacement. Clin Orthop 1996;329 (Suppl):290-6.

9. Mcgregor DB, Baan RA, Partensky C, Rice JM, Wilbourn JD. Evaluation of the carcinogenic risks to humans associated with surgical implants and other foreign bodies: a report of an IARC monographs programme meeting. Eur J Cancer 2000;36 307-13

10. Singh J, Snow ET. Chromium (III) decreases the fidelity of human DNA polymerase beta. Biochemistry 1998;37:9371-8.

11. Luo H, Lu Y, Shi X, Mao Y, Dalaal NS. Chromium (IV)-mediated fenton-like reaction causes DNA damage: implication to genotoxicity of chromate. Ann Clin Lab Sci 1996; 26:185-91.

12. Kortenkamp A, Casadevall M, Da CruzFresco P. The reductive conversion of the carcinogen chromium (VI) and its role in the fomation of DNA lesions. Ann Clin Lab Sci 1996;26:160-75

13. Case CP, Langkamer VG, Howell RT, et al. Preliminary observations on possible premalignant changes in bone marrow adjacent to worn total hip arthroplasty implants. Clin Orthop 1996;329 (Suppl):269-79.

14. Doherty AT, Howell RT, Ellis LA, et al. Increased chromosome aberrations in peripheral blood lymphocytes of patients having revision arthroplasty of the hip. J Bone Joint Surg [Br] 2001;83-B:1075-81.

15. Fenech M. Chromosome biomarkers of genomic instability relevant to cancer. Drug Discov Today 2002;15:1128-37.

16. Fenech M. Biomarkers of genetic damage for cancer epidemiology. Toxicology 2002 181:411-6.

17. Speit G. Appropriate in vitro test conditions for genotoxicity testing of fibres. Inhal Toxicol 2002;14:79-90.

18. Ellard S, Toper S, Stemp G, et al. A comparison of conventional metaphase analysis of Giemsa-stained chromosomes with multi-colour fluorescence in situ hybridization analysis to detect chromosome aberrations induced by daunmycin. Mutagenesis 1996;11:537-46.

19. Doherty AT, Lewis B, Howell RT, Langkamer G, Case CP. Wear debris from adjacent to failed total hip arthroplasty induces metal specific aberrations in the in vitro micronucleus assay. Mutageneis 2004; in press

20. Doherty AT, Ellard S, Parry EM, Parry JM. A study of the aneugenic activity of trichlorfon detected by centromere-specific probes in human lymphoblastoid cel lines. Mutat Res 1996;372:221-31 
21. Case CP, Ellis L, Turner JC, Fairman B. Development of a routine method for the determination of trace metals in whole blood by magnetic sector inductively coupled plasma mass spectrometry with particular relevance to patients with total hip and knee arthroplasty. Clin Chem 2001;47:275-80.

22. Doherty AT, Howell T, Ellis LA, et al. Increased chromosome translocations and aneuploidy in peripheral blood lymphocytes of patients having revision arthroplasty of the hip. J Bone Joint Surg [Br] 2001;83-B:1075-81.

23. Mothersill C, Seymour CB. Commentary, mechanisms and implications of genome instability and other delayed effects of ionizing radiation exposure. Mutagenesis 1998;13:421-6.
24. Wright E. Inherited and inducible chromosomal instability: a fragile bridge between genome integrity mechanisms and tumourigenesis. J Pathol 1999;187: 19-27.

25. Coen N, Kadhim MA, Wright EG, Case CP, Mothersill CE. Particulate debris from a titanium metal prosthesis induces genomic instability in primary human fibroblast cells. Br J Cancer 2003;88:548-52.

26. Lorimore SA, Coates PJ, Milne G, Wright EG. Inflammatory-type responses after exposure to ionizing radiation in vivo: a mechanism for radiation-induced bystander effects? Oncogene 2001;20:7085-95. 